\title{
Impact of stress coping capacity on recovery from abdominal hysterectomy in a fast-track programme: a prospective longitudinal study
}

Preben Kjölhede, Ninnie Borendal Wodlin, Lena Nilsson, Mats Fredrikson and Klaas Wijma

\section{Linköping University Post Print}

N.B.: When citing this work, cite the original article.

This is the authors' version of the following article:

Preben Kjölhede, Ninnie Borendal Wodlin, Lena Nilsson, Mats Fredrikson and Klaas Wijma, Impact of stress coping capacity on recovery from abdominal hysterectomy in a fast-track programme: a prospective longitudinal study, 2012, British Journal of Obstetrics and Gynecology, (119), 8, 998-1007.

which has been published in final form at:

http://dx.doi.org/10.1111/j.1471-0528.2012.03342.x

Copyright: Wiley-Blackwell http://eu.wiley.com/WileyCDA/Brand/id-35.html

Postprint available at: Linköping University Electronic Press http://urn.kb.se/resolve?urn=urn:nbn:se:liu:diva-79789 


\title{
Impact of stress coping capacity on recovery from abdominal hysterectomy in a fast track program: a prospective longitudinal study
}

by

\author{
${ }^{1}$ Preben KJØLHEDE, ${ }^{1}$ Ninnie BORENDAL WODLIN, ${ }^{2}$ Lena NILSSON, \\ ${ }^{3,4}$ Mats FREDRIKSON \& ${ }^{5}$ Klaas WIJMA
}

${ }^{1}$ Division of Obstetrics and Gynaecology, Department of Clinical and Experimental Medicine, Faculty of Health Sciences, Linköping University, Department of Obstetrics and Gynaecology, County Council of Östergötland, S - 58185 Linköping, Sweden

${ }^{2}$ Division of Drug Research, Anaesthesiology and Intensive Care, Department of Medical and Health Sciences, Linköping University. Department of Anaesthesia and Intensive Care, County Council of Östergötland, S - 58185 Linköping, Sweden

${ }^{3}$ Linköping Academic Research Centre, University Hospital, S - 58185 Linköping, Sweden

4 Division of Occupational and Environmental Medicine, Department of Experimental and Clinical Medicine, Faculty of Health Sciences, Linköping University, S - 58185 Linköping, Sweden

${ }^{5}$ Unit of Medical Psychology, Department of Clinical and Experimental Medicine, Faculty of Health Sciences, Linköping University, S- 58185 Linköping, Sweden

Corresponding author:

Preben Kjølhede, MD, $\mathrm{PhD}$

Department of Obstetrics and Gynaecology

University Hospital

S-581 85 Linköping

Sweden

Phone +46101030000

Fax +4613148156

E-mail Preben.Kjolhede@liu.se

Running title: Stress coping capacity and fast track abdominal hysterectomy 


\begin{abstract}
Objective: To evaluate the effect of stress coping capacity in combination with mode of anaesthesia on postoperative recovery in fast track abdominal hysterectomy.

Design: Prospective longitudinal study.

Setting: Five hospitals in the South-East of Sweden.

Population: One-hundred sixty-two women undergoing fast track abdominal hysterectomy for benign conditions.

Methods: Self-administered questionnaires, the Stress Coping Inventory (SCI) and the Swedish Postoperative Symptom Questionnaire (SPSQ), and clinical information collected prospectively. Stress coping capacity was categorized as high and low according to the sum score of the SCI. Comparisons of effect variables were adjusted using a propensity score matching model.
\end{abstract}

Main outcome measures: Associations between stress coping capacity and hospital stay, sick leave, use of analgesic, and self-reported postoperative symptoms.

Results: Women with high stress coping capacity had a significantly shorter sick leave, experienced postoperative symptoms significantly less often and with lower intensity than women with low stress coping capacity. This was almost exclusively related to having had the operation under spinal anaesthesia. Hospital stay, use of analgesics and having abdominal pain were not related to stress coping capacity.

Conclusions: As was shown for almost all variables, in patients for whom spinal anaesthesia was applied, high stress coping seems to be a quality that helps the patients to manage the burden of surgery. It is desirable for the individual as well as for the health care system to enhance recovery by using intervention programs designed to improve or manage stress coping, particularly for individuals with low stress coping capacity. This recommendation merits further investigation. 
Keywords: fast-track; general anaesthesia; abdominal hysterectomy; spinal anaesthesia; stress coping capacity

The study was registered in ClinicalTrial.gov Protocol Registration System (NCT00527332) with initial release September 7; 2007. 


\section{Introduction}

Abdominal hysterectomy is a common gynaecological operation [1] mostly carried out for benign conditions such as bleeding disturbances and/or uterine fibroids. The complex nature of hysterectomy suggests that multiple factors are likely to influence postoperative recovery. Psychological problems often decrease a woman's capacity to cope with symptoms from surgery that would otherwise be tolerable, and are related to more subjective feelings of distress. This may interfere with treatment and delay recovery [2]. The experience and intensity of postoperative symptoms are related to the capacity to cope with stressful situations; women with lower stress coping capacity have greater problems recovering after surgery than those with a higher stress coping capacity [3-5].

During the past 10 years, fast track surgery has gained much attention. Fast track surgery is intended to enhance recovery [6]. By giving the patient thorough and detailed information about the operation and the post-operative period, the fast track program prepares the individual for a faster recovery [7]. Providing accurate information prior to gynaecological surgery and using regional anaesthesia reduces postoperative analgesic requirements and results in a more rapid return to full health $[7,8]$.

The connection between stress coping capacity and postoperative recovery in fast track programs has not been evaluated, however. As the recovery time after fast track surgery is shorter than after traditionally conducted surgery, it seems reasonable to assume that the physical burden for the patient will be lower. Therefore, one could theorize that a fast track program, by reducing the physical problems for the patient, could also be expected to place fewer demands on a patient's stress coping capacity during the postoperative recovery.

We conducted an open randomized multicentre trial comparing general anaesthesia and spinal anaesthesia in fast track abdominal hysterectomy for benign conditions (the "GASPI study"), in order to analyse postoperative recovery. The results of the primary and secondary 
objectives of that trial that have previously been presented [9-11] showed a significantly better outcome for patients given spinal anaesthesia, with fewer perceived symptoms postoperatively, a faster recovery of quality of life and a shorter sick leave. There was, however, no significant difference between the two groups as concerns length of hospital stay. Assuming that the mode of anaesthesia and psychological characteristics were responsible for the benefits observed in postoperative recovery, it might have been expected that even the duration of hospital stay would have been shortened. The results from "the GASPI study" indicate that the length of hospital stay in a fast track program as measured using standardized discharge criteria was not significantly affected by mode of anaesthesia or by the psychological characteristics of the patients. We therefore wondered if the fast track program may have counteracted the predicted relationship between psychological traits and duration of hospital stay.

Based on these considerations we hypothesized that in a fast track regime the difference in recovery measures that otherwise could be anticipated after abdominal hysterectomy between women with low and high stress coping capacity would disappear.

This study of women who had fast track abdominal hysterectomy is a secondary post hoc analysis of the "GASPI study". The aim of this study was to examine the role of stress coping capacity, in combination with mode of anaesthesia, in affecting recovery from surgery. Recovery from surgery was operationalized by measuring the duration of hospital stay, sick leave, use of analgesic, and self-reported postoperative symptoms and by taking into account the mode of anaesthesia, either general or spinal anaesthesia. 


\section{Methods}

The population in this study comprises a cohort of women who all had an abdominal hysterectomy for benign diseases in a fast track program. The women participated in an open randomized controlled multicentre study that compared general anaesthesia and spinal anaesthesia including intrathecal morphine [9]. The trial was conducted in five hospitals in the South-East of Sweden during March 2007 to December 2009. Ethical approval was obtained from the Regional Ethical Review Board in Linköping.

Women admitted to the hospitals for hysterectomy for benign conditions were assessed for eligibility in the study. Inclusion criteria were: age 18-60 years; scheduled for abdominal total or subtotal hysterectomy; benign indications (cervical dysplasia included); at least one ovary preserved at conclusion of surgery; speaking Swedish fluently. Exclusion criteria were: contraindication against spinal or general anaesthesia; American Society of Anesthesiologists (ASA) score $\geq 3$; gynaecological malignancy present or in history; previous bilateral oophorectomy; operation expected to encompass more than hysterectomy with or without salpingectomy and appendectomy; postmenopausal without hormone therapy (if patient was on hormone therapy, this therapy was to be maintained for six months postoperatively); physically disabled to a degree which might be expected to affect mobilization postoperatively; severe psychiatric disease or mentally disabled. The patients accepted participation in the study by signing informed consent.

The enrolled women were randomized to surgery under general anaesthesia or spinal anaesthesia with intrathecal morphine. One hundred and eighty women were randomized and 162 completed the study (Figure 1).

The fast track program and the standardized modes of anaesthesia have previously been presented and described in detail $[9,10]$. All women received similar information about care 


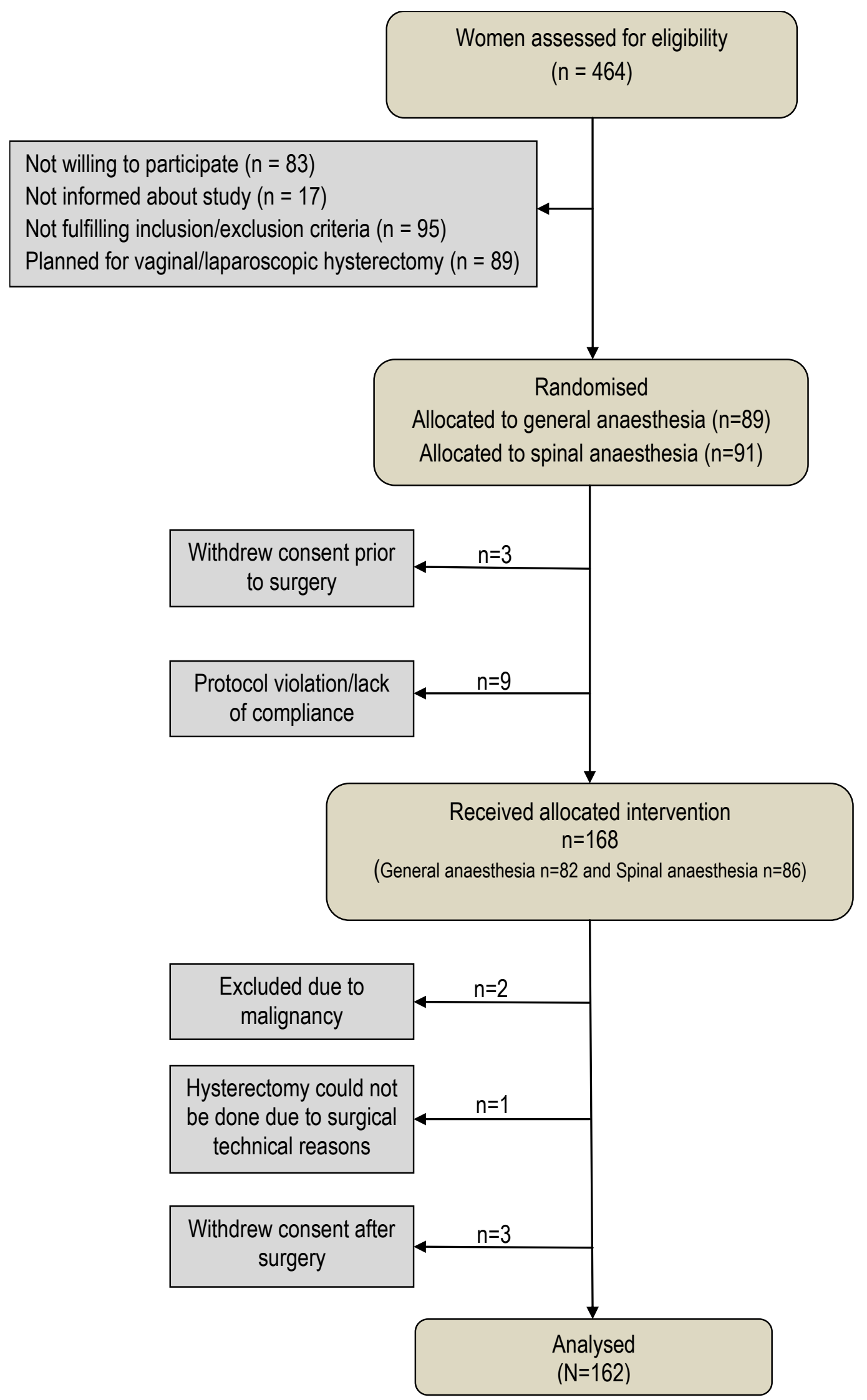

Figure 1. Flowchart of the study participants. 
and advice for the peri-operative period. The postoperative monitoring of the two groups was identical.

The duration of hospital stay was defined as the time from start of anaesthesia to the time of discharge from the Gynaecological Ward. Clinical data were collected consecutively during the hospital stay and at follow-up visits five weeks and six months postoperatively. After discharge the women completed a diary reporting their use of analgesics until the 5week post-operative follow-up visit. The total amount of analgesics given during the hospital stay and after discharge until five weeks post-operatively was summarized.

\section{Assessment of stress coping capacity}

The capacity to cope with stress was measured approximately one week pre-operatively by the Stress Coping Inventory (SCI) $[12,13]$. The respondent rates how often she thinks she is able to cope with each of the 41 stressful situations described in the SCI form [13]. The answers are rated on a 6-point Likert type scale, ranging from 'almost never' (1), 'rarely‘ (2), 'occasionally‘ (3), 'rather often‘ (4), 'very often` (5) to 'almost always' (6). The minimum sum score is 41 and the maximum 246. The higher the sum score, the greater the stress-coping capacity. The sum score was calculated after the study period and was thus blinded for the participants and investigators during the study. A clinical categorization of the SCI sum score has not been scientifically evaluated, but the value of the lower $25^{\text {th }}$ percentile has been considered as a discriminatory level for low and high stress coping capability [14]. In this study we used the lower $25^{\text {th }}$ percentile (sum score $\leq 169$ ) as cut-off for low and high stress coping capacity.

In a previous study [13] the SCI showed the following correlations with four commonly used psychological questionnaires: Beck Depression Inventory [15], $r=-0.53$ (95\% CI -0.65 -0.39); State-Trait Anxiety Inventory [16], r= -0.71, (95\% C I-0.79 - -0.60); Psychological Well Being Inventory [17], $\mathrm{r}=0.57,(95 \%$ CI $0.43-0.68)$ and Women's Health 
Questionnaire [18], $\mathrm{r}=-0.55$ (95\% CI -0.66--0.41). The internal consistency of the SCI has been found to be very good, with Cronbach's alpha's at 0.94 to 0.95 and a split-half reliability at $0.93[5,12,14]$.

\section{Assessment of postoperative symptoms}

Postoperative symptoms were assessed by the Swedish Postoperative Symptoms

Questionnaire (SPSQ) [19]. The patient completed the form on a daily basis, preferably in the evening during the first seven days postoperatively, starting in the evening after surgery (day 0 ) and thereafter once weekly until the 5-week postoperative visit. The questions were both open- and closed-ended. The closed-ended questions could be answered by choosing an answer from a set given on a Likert type scale. The open-ended questions required written responses.

Initially the patient was asked if she at the moment of completing the form experienced a number of symptoms commonly reported after surgery (pain in the area of surgery, nausea, retching, headache, abdominal pain, tiredness, drowsiness and blurred vision) and how she rated the intensity of each of these symptoms. The answers were rated on a 4-point scale: 'none' (0), 'yes, a little' (1), 'yes, somewhat' (2), and 'yes, a lot' (3), and a sum score (SPSQ sum score) was calculated in order to estimate the overall postoperative discomfort. Second, the patient was asked to report the intensity of pain in the surgical area $a$ ) when it was at its worst and $b$ ) how it was felt on average on the particular day. The answers to these questions were rated on a 7-point scale as: 'none' (0), 'very mild' (1), 'mild' (2), 'moderate' (3), 'bad' (4), 'severe' (5), and 'very severe' (6). Third, the patient reported occurrence and comprehensive intensity of eight specified troublesome symptoms ('nausea/vomiting (PONV)'; 'headache“; 'abdominal pain“; 'drowsiness'; 'fatigue‘; 'blurred vision“; 'itching' and 'others' $)$. Assessments similar to those for intensity of pain in surgical area were made. 
For the analyses in this study, we used the mean values of the repeated estimates carried out within the five weeks (i.e. on 12 occasions) of: a) the SPSQ sum score of the intensity of symptoms the patients experienced at the moment of completing the form; $b$ ) the average intensity of pain in the surgical area and of troublesome symptoms, and c) the occurrence of troublesome symptoms. In order to assess the impact of stress coping capacity on effect variables more generally and not only at the moment or during a short time period we selected only those troublesome symptoms that occurred with a frequency of more than $10 \%$ and were sustained for more than a week.

\section{Sick leave}

At discharge from the hospital the patient was granted sick leave for 14 days. The research nurse contacted the patient by telephone the day after discharge and then once weekly until the visit five weeks postoperatively. The purpose of the frequent contacts was dual; to be supportive and to provide a reminder to fill in the study questionnaires. At these contacts the sick leave was prolonged by at most seven days at a time on the basis of patient demand until the patient was able to return to work or felt sufficiently recovered. Duration of the sick leave was defined as the time from the day of surgery to the day of return to work to the same extent as preoperatively. Women, who were on sick leave for reasons other than the hysterectomy, were unemployed or had disability pension were excluded from the analysis of sick leave.

\section{Statistics}

Estimation of sample size and power calculation were based on the primary outcome measure of the trial, duration of hospital stay, and have previously been described [9]. No power calculations were done a priori for the secondary outcomes.

All analyses were done according to intention-to-treat principles. Data are denoted as median and range or number and percentage. Mann Whitney U-tests were used for analyses of 
effect variables on a continuous scale. Nominal data were compared by using Yates corrected $\chi 2$ - tests or Fishers`'Exact tests as appropriate.

As the women with low and high stress coping capacity were not randomly assigned to the modes of anaesthesia potential confounding effects might be present which could influence the results. In order to reduce or eliminate potential confounding effects a propensity score matching analysis was conducted $(20,21)$. The propensity scores were calculated with a logistic regression analysis with low or high stress coping capacity as outcome and age, BMI, parity, previous anaesthesia, concomitant diseases, main indication of hysterectomy, ASA, mode of hysterectomy, mode of skin incision and mode of anaesthesia as independent factors. The women in the low stress coping capacity group were then matched to women from the high stress coping capacity group based on the propensity score in a 1:1 matching procedure. To match each woman with low stress coping capacity we used a woman with high stress coping capacity that had an identical propensity score. In case this was not found we used the woman with the closest propensity score. The data from these matched women were entered into a linear regression analysis to adjust for potential confounding (propensity score). To take the matching into account each matched pair had a unique number that was used as identity in a regression model for panel data (Stata v 12.0, StataCorp LP, College Station, TX, USA).

Since some of the dependent variables were not normally distributed, logarithmic transformations were used for these variables. 


\section{Results}

Of the 162 women who completed the study 42 women were categorized as having a low stress coping capacity, i.e. having a SCI sum score $\leq 169$, constituting the Low Stress Capacity Group (LSC-G), and 120 having high stress coping capacity (SCI sum score > 169), constituting the High Stress Capacity Group (HSC-G). The median SCI sum score of the LSC-G was 154 (107-169) and 194 (170-241) for the HSC-G. The SCI sum scores did not differ significantly between women who had the operation performed under general anaesthesia (GA) and those with spinal anaesthesia (SA); (183 (107-241) for GA and 187 (121-241) for SA; $\mathrm{p}=0.532)$ ). Demographic, descriptive and clinical data of the two stress coping capacity groups are presented in Table 1.

The results for effect variables subdivided by categorisation of stress coping capacity are presented in Table 2 and for the effect variables subdivided by mode of anaesthesia and categorisation of stress coping capacity in Table 3.

\section{OBJECTIVE EFFECT MEASURES}

\section{Duration of hospital stay}

Overall and subdivided after mode of anaesthesia the duration of hospital stay did not differ significantly between women in the two stress coping capacity groups.

\section{Sick leave}

Of the 162 women in the study 151 received a sick leave, 113 in the HSC-G and 38 in the LSC-G. Of the eleven women who did not receive a sick leave, seven were on disability pension and four were on sick leave for reasons other than the hysterectomy.

The duration of sick leave was strongly associated with the stress coping capacity, being significantly shorter for women in the HSC-G than in the LSC-G. This association was strongly connected to mode of anaesthesia. In the group of women who underwent hysterectomy in SA, the length of sick leave in the HSC-G was significantly shorter than for 
Table 1. Demographic, descriptive and clinical data.

\begin{tabular}{|c|c|c|c|}
\hline Characteristics & $\begin{array}{l}\text { Low stress } \\
\text { capacity group } \\
(\mathrm{n}=42)\end{array}$ & $\begin{array}{l}\text { High stress } \\
\text { capacity group } \\
(n=120)\end{array}$ & $p$-value \\
\hline Age (years) & $44.5(33-58)$ & $46.0(34-58)$ & $0.150 \dagger$ \\
\hline Body mass index (kg/m²) & $26.4(18.9-41.5)$ & $25.1(19 .-39.2)$ & $0.238 \dagger$ \\
\hline Parity & $2.0(0-4)$ & $2.0(0-8)$ & $0.752 \dagger$ \\
\hline Smokers & $7(16.7 \%)$ & $22 \quad(18.3 \%)$ & $0.993^{\dagger \dagger}$ \\
\hline Previous laparotomy (no. of women) & $17(40.5 \%)$ & $41 \quad(34.2 \%)$ & $0.584^{\dagger \dagger}$ \\
\hline \multicolumn{4}{|l|}{ Previous anaesthesia*: } \\
\hline General anaesthesia & $15(35.7 \%)$ & $27 \quad(22.5 \%)$ & $0.140 \dagger$ \\
\hline Spinal/epidural anaesthesia & $5 \quad(11.9 \%)$ & $17 \quad(14.2 \%)$ & $0.915^{\dagger \dagger \dagger}$ \\
\hline \multicolumn{4}{|l|}{ Concomitant diseases*: } \\
\hline Psychiatric & $8 \quad(19.0 \%)$ & $6 \quad(5.0 \%)$ & $0.014^{\dagger \dagger}$ \\
\hline Musculoskeletal & $5(11.9 \%)$ & $12(10.0 \%)$ & $0.772^{\dagger \dagger \dagger}$ \\
\hline Cardiovascular & $5(11.9 \%)$ & $12(10.0 \%)$ & 0.772 †† \\
\hline Chronic pulmonary & $5 \quad(11.9 \%)$ & $5 \quad(4.2 \%)$ & 0.128 \\
\hline \multicolumn{4}{|l|}{ Concomitant medication: } \\
\hline Analgesics & $9(21.4 \%)$ & $23(19.2 \%)$ & $0.927^{\dagger \dagger}$ \\
\hline Antidepressants & $7(16.7 \%)$ & $6(5.0 \%)$ & $0.040^{\dagger \dagger}$ \\
\hline \multicolumn{4}{|l|}{ Main indication of hysterectomy: } \\
\hline Bleeding disturbances & $30(71.4 \%)$ & $62(51.7 \%)$ & \multirow{4}{*}{$0.088^{\dagger \dagger}$} \\
\hline Mechanical symptoms & $11(26.2 \%)$ & $45(37.5 \%)$ & \\
\hline CIN/endometrial hyperplasia & $0(0.0 \%)$ & $9 \quad(7.5 \%)$ & \\
\hline Endometriosis/dysmenorrhea & $1(2.4 \%)$ & $4 \quad(3.3 \%)$ & \\
\hline \multicolumn{4}{|l|}{ ASA\#: } \\
\hline Class I & $24(57.1 \%)$ & $90(75.0 \%)$ & \multirow{2}{*}{$0.047^{\dagger \dagger}$} \\
\hline Class II & $18(42.9 \%)$ & $30(25.0 \%)$ & \\
\hline \multicolumn{4}{|l|}{ Mode of hysterectomy: } \\
\hline Total abdominal & $27(64.3 \%)$ & $79(65.8 \%)$ & \multirow{2}{*}{$1.000^{\dagger \dagger}$} \\
\hline Subtotal abdominal & $15(35.7 \%)$ & $41(34.2 \%)$ & \\
\hline \multicolumn{4}{|l|}{ Mode of skin incision: } \\
\hline Midline & $3(7.1 \%)$ & $10(8.3 \%)$ & \multirow{2}{*}{$1.000^{\S}$} \\
\hline Low transverse & $39(92.9 \%)$ & $110(91.7 \%)$ & \\
\hline \multicolumn{4}{|l|}{ Mode of anaesthesia: } \\
\hline General anaesthesia & $20(47.6)$ & $60(50 \%)$ & \multirow{2}{*}{$0.931^{\dagger \dagger}$} \\
\hline Spinal anaesthesia & $22(52.4)$ & $60(50 \%)$ & \\
\hline
\end{tabular}

Figures denote median and (range) or number and (\%).

* A woman may have had more anaesthesia or concomitant diseases. ${ }^{*}=\mathrm{CIN}$ cervical intraepithelial dysplasia.

\#\#=ASA the American Society of Anesthesiologist classification of physical status. $\uparrow$ Mann-Whitney U-test. $\dagger \dagger$

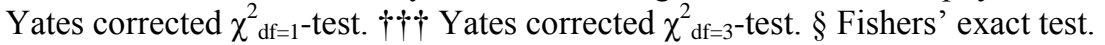


Table 2. Results associated with measures performed by the health care system and with estimates performed by the study participants in relation to category of stress coping capacity.

\begin{tabular}{|c|c|c|c|c|}
\hline & $\begin{array}{l}\text { LSC-G } \\
(n=42)\end{array}$ & $\begin{array}{l}\text { HSC-G } \\
(n=120)\end{array}$ & $p$-value \# & $\begin{array}{c}\text { Adjusted } \\
p \text {-value } \\
(\mathrm{n}=42+42)\end{array}$ \\
\hline \multicolumn{5}{|l|}{ Measures performed by the health care system } \\
\hline Duration of hospital stay (hours) & $50.2(24.4-124.6)$ & $47.2(21.9-123.4)$ & 0.227 & 0.893 \\
\hline Duration of sick leave (days) & $29.0(14-81)$ & $23.0(2-258)$ & 0.001 & 0.003 \\
\hline Analgesics. Equivalent morphine $(\mathrm{mg}){ }^{*}$ & $15.0(0-130.0)$ & $15.0(0-255.4)$ & 0.969 & 0.631 \\
\hline Analgesics. Non-opioids (sum of RDD) ** & $19.4(1.8-58.0)$ & $17.2(2.4-47.6)$ & 0.037 & 0.062 \\
\hline \multicolumn{5}{|l|}{ Estimates performed by the study participants } \\
\hline SPSQ sum-score (min - max sum score 0 - 24) & $5.1(1.4-12.3)$ & $3.6(0-8.6)$ & 0.003 & 0.002 \\
\hline Intensity of pain in surgical area (scale $0-6$ ) & $2.3(0.9-3.5)$ & $1.7(0.1-5.0)$ & 0.001 & 0.001 \\
\hline Intensity of troublesome symptoms (scale $0-6$ ) & $2.3(0.5-3.6)$ & $1.8(0.2-5.0)$ & 0.002 & 0.004 \\
\hline Abdominal pain (occurrence (\%)) & $58(0-100)$ & $42(0-100)$ & 0.062 & 0.090 \\
\hline Fatigue (occurrence (\%)) & $29(0-100)$ & $17(0-100)$ & 0.009 & 0.036 \\
\hline
\end{tabular}

Figures present median and range. \# Mann-Whitney U-test. ${ }^{\#}$ Regression analysis, adjusted for matched propensity score. * total consumption for 16 days postoperatively. ** total consumption for five weeks postoperatively. HSC-G and LSC-G = high, respective low, stress coping capacity group; RDD = recommended daily doses; SPSQ = Swedish Postoperative Symptom Questionnaire. 
Table 3. Results associated with measures performed by the health care system and with estimates performed by the study participants in relation to category of stress coping capacity and subdivided according to mode of anaesthesia.

\begin{tabular}{|c|c|c|c|c|c|c|c|c|}
\hline & \multicolumn{3}{|c|}{ Spinal anaesthesia } & \multicolumn{5}{|c|}{ General anaesthesia } \\
\hline & $\begin{array}{l}\text { LSC-G } \\
(n=22)\end{array}$ & $\begin{array}{l}\text { HSC-G } \\
(n=60)\end{array}$ & $p$-value ${ }^{\#}$ & $\begin{array}{l}\text { Adjusted } \\
p \text {-value } \\
(n=22+22)\end{array}$ & $\begin{array}{l}\text { LSC-G } \\
(n=20)\end{array}$ & $\begin{array}{l}\text { HSC-G } \\
(n=60)\end{array}$ & $p$-value $\#$ & $\begin{array}{l}\text { Adjusted } \\
\text { p-value } \\
(n=20+20)\end{array}$ \\
\hline \multicolumn{9}{|l|}{ Measures performed by the health care system } \\
\hline Duration of hospital stay (hours) & $\begin{array}{l}51.4 \\
(26.3-124.6)\end{array}$ & $\begin{array}{l}34.0 \\
(21.9-123.4)\end{array}$ & 0.016 & 0.220 & $\begin{array}{l}49.1 \\
(24.4-80.4)\end{array}$ & $\begin{array}{l}50.5 \\
(24.5-100.3)\end{array}$ & 0.383 & 0.079 \\
\hline Duration of sick leave (days) & $\begin{array}{l}29.0 \\
(14-81)\end{array}$ & $\begin{array}{l}19.5 \\
(2-258)\end{array}$ & 0.001 & 0.001 & $\begin{array}{l}30.5 \\
(20-49)\end{array}$ & $\begin{array}{l}28.0 \\
(7-81)\end{array}$ & 0.219 & 0.100 \\
\hline Analgesics. Equivalent morphine (mg) * & $\begin{array}{l}4.5 \\
(0-113.3)\end{array}$ & $\begin{array}{l}2.5 \\
(0-255.4)\end{array}$ & 0.392 & 0.380 & $\begin{array}{l}20.5 \\
(7.5-130.0)\end{array}$ & $\begin{array}{l}25.2 \\
(5.0-243.5)\end{array}$ & 0.414 & 0.154 \\
\hline Analgesics. Non-opioids (sum of RDD) ** & $\begin{array}{l}19.4 \\
(5.8-58.0)\end{array}$ & $\begin{array}{l}15.4 \\
(3-2-46.5)\end{array}$ & 0.042 & .0 .042 & $\begin{array}{l}19.2 \\
(1.8-56.7)\end{array}$ & $\begin{array}{l}18.6 \\
(2.4-47.6)\end{array}$ & 0.243 & 0.255 \\
\hline \multicolumn{9}{|l|}{ Estimates performed by the study participants } \\
\hline SPSQ sum-score (sum score 0 - 24) & $\begin{array}{l}5.1 \\
(1.4-12.3)\end{array}$ & $\begin{array}{l}3.0 \\
(0-8.5)\end{array}$ & 0.001 & 0.007 & $\begin{array}{l}4.8 \\
(1.9-10.0)\end{array}$ & $\begin{array}{l}4.1 \\
(1.3-8.6)\end{array}$ & 0.353 & 0.296 \\
\hline Intensity of pain in surgical area (scale $0-6$ ) & $\begin{array}{l}2.2 \\
(0.9-3.5)\end{array}$ & $\begin{array}{l}1.6 \\
(0.1-3.3)\end{array}$ & 0.002 & 0.008 & $\begin{array}{l}2.4 \\
(1.3-3.3)\end{array}$ & $\begin{array}{l}1.9 \\
(0.3-5.0)\end{array}$ & 0.055 & 0.030 \\
\hline Intensity of troublesome symptoms (scale $0-6$ ) & $\begin{array}{l}2.3 \\
(0.6-3.4)\end{array}$ & $\begin{array}{l}1.8 \\
(0.2-3.3)\end{array}$ & 0.005 & 0.053 & $\begin{array}{l}2.4 \\
(0.5-3.6)\end{array}$ & $\begin{array}{l}1.9 \\
(0.3-5.0)\end{array}$ & 0.101 & 0.011 \\
\hline Abdominal pain (occurrence (\%)) & $\begin{array}{l}50 \\
(0-100)\end{array}$ & $\begin{array}{l}42 \\
(0-100)\end{array}$ & 0.403 & 0.878 & $\begin{array}{l}71 \\
(17-100)\end{array}$ & $\begin{array}{l}54 \\
(0-100)\end{array}$ & 0.076 & 0.007 \\
\hline Fatigue (occurrence (\%)) & $\begin{array}{l}29 \\
(0-100)\end{array}$ & $\begin{array}{l}8 \\
(0-100)\end{array}$ & 0.019 & 0.007 & $\begin{array}{l}29 \\
(0-83)\end{array}$ & $\begin{array}{l}25 \\
(0-92)\end{array}$ & 0.277 & 0.915 \\
\hline
\end{tabular}

Figures present median and range.

\# Mann-Whitney U-test. \#\# Regression analysis adjusted for matched propensity score.* total consumption for 16 days postoperatively. ${ }^{* *}$ total consumption for five weeks postoperatively. HSC-G and LSC-G = high, respective low, stress coping capacity group; RDD = recommended daily doses; SPSQ = Swedish Postoperative Symptom Questionnaire; 
the women in the LSC-G, whereas for the women who had the operation under GA no such difference was observed.

\section{Consumption of analgesics}

The consumption of opioids and the use of non-opioids (sum of recommended daily doses (RDD)) did not differ significantly between the two stress coping capacity groups overall or in the SA and GA subgroups.

Although the women who had the hysterectomy under GA consumed significantly more opioids postoperatively and equally amount of non-opioids than those who had the operation in SA (equivalent morphine: $23.9 \mathrm{mg}(5.0-243.5 \mathrm{mg})$ vs. $3.0 \mathrm{mg}(0.0-255.4 \mathrm{mg}) ; \mathrm{p}<0.0001$, and non-opioids (sum of RDD): 18.4 (1.8-56.7) vs. 17.0 (3.2-58.0); $\mathrm{p}=0.196)$ no significant differences were observed in consumption of opioids or non-opioids between the low and high stress capacity groups in either of the modes of anaesthesia.

\section{SUBJECTIVE EFFECT MEASURES}

\section{Postoperative symptoms}

The LSC-G had significantly higher SPSQ sum score, pain intensity on average, and intensity on average of troublesome symptoms than the HSC-G. When adjusted for mode of anaesthesia, no significant differences were observed in any of these three outcome measures between the two groups LSC-G and HSC-G among those who had the operation performed under GA. However, the LSC-G women who had the operation conducted in SA did experience significantly more symptoms with higher intensity than the HSC-G women

Only the symptoms abdominal pain and fatigue reached the level of a frequency of $10 \%$ or more and were sustained for more than a week. Overall the mean frequencies of the troublesome symptom 'abdominal pain' and 'fatigue' did not differ significantly between the LSC-G and HSC-G (Table 2). 
The influences of mode of anaesthesia on the prevalence of the two troublesome symptoms 'abdominal pain' and 'fatigue' in relation to low and high stress coping capacity varied as illustrated in Table 3. Although there were no significant difference in occurrence of abdominal pain between the women who had GA and SA (63\% (0-100\%) vs. $42 \%(0-100 \%)$; $\mathrm{p}=0.014$ ), the LSC-G women who had GA had a significantly higher occurrence of abdominal pain than the HSC-G. No such difference was observed among the women who had the operation performed in SA. Contrarily, fatigue occurred significantly more often in the women who had GA compared with SA $(25 \%$ (0-92\%) vs. $8 \%(0-100 \%)$; $\mathrm{p}=0.005)$. By subdividing after mode of anaesthesia the LSC-G women showed a significantly higher occurrence of fatigue than the HSC-G women in the group who received SA whereas no such difference was seen in the GA group. 


\section{Discussion}

The length of recovery after abdominal hysterectomy in a fast track program was found to be associated with stress coping capacity, but only in the spinal anaesthesia group. As was shown for almost all variables for the patients for whom spinal anaesthesia was used, high stress coping seemed to be a quality that facilitated the management of the burden of surgery. Only the use of analgesics and having abdominal pain were not related to stress coping.

Many studies have explored the relationship between preoperative psychological factors and post-operative recovery, with ambiguous findings [3,5,22-25]. Fast track programs had not been used in all the groups covered by these studies. It is not clear whether fast track programs have any impact on a possible correlation of pre-operative psychological characteristics and recovery.

Stress coping capacity did not appear to be of value for recovery for women who had general anaesthesia. Patients' stress coping capacity had significance only when they had spinal anaesthesia. One explanation could be that the women who had the operation under general anaesthesia developed postoperative cognitive dysfunction (POCD) to a greater degree than those who had spinal anaesthesia. This coheres with the findings of Rasmussen et al. [26]. POCD affects a wide variety of cognitive functions such as attention, memory executive function and speed of information processing [27]. The aetiology remains elusive but POCD has been connected with effects of general anaesthesia and the post-operative use of opioids. A multimodal approach within fast track principles of pain management with reduced opioids combined with a reduction in inflammatory responses with minimal invasive surgery and pharmacological anti-inflammatory intervention may therefore have a potential for improving postoperative cognitive function [28]. The women in the general anaesthesia group had significantly more symptoms postoperatively and used five to ten times more morphine equivalent analgesics postoperatively than those who had spinal anaesthesia. This 
might indicate that the intensity of their suffering and POCD overruled their stress coping capacity. Another concurrent factor could be that patients' stress coping capacity is of use when the patient is awake or sedated during spinal anaesthesia. A patient who is submitted to surgery has to cope with various emotions and cognitions and has to use her will to force herself to be compliant and committed. A patient who has a higher capacity to stand uncertainties and believes more in her own power to manage is better prepared for such unsafe situation.

The length of hospital stay after surgery is mainly determined by clinical and medical criteria and therefore is assumed to be less likely influenced by pre-operative psychological characteristics, in particular when the hospital stay is supposed to be short, as in fast track programs. Oxlad et al. reported that psychological factors like anxiety, depression and posttraumatic stress disorder comprise a risk for prolonged hospital stay in coronary bypass surgery [29]. We found that hospital stay was not related to the stress coping capacity independent of mode of anaesthesia. It was pointed out in the fast track program and in the information given repeatedly peri-operatively that discharge was allowed when the standardized criteria for discharge were met. This was an attempt to encourage the women to leave the clinic as soon as the criteria were fulfilled. It seemed that the women independent of stress coping capacity and mode of anaesthesia complied and felt reassured about this.

The length of sick leave may be considered as a blunt measurement of recovery since it is usually not strictly determined by medical decisions. Social welfare benefits, local traditions, personal reasons, workload and the attitudes of professionals in the healthcare system may all have an effect on the length of the sick leave. In the present study the participants had weekly telephone contacts with the research nurses and prolongation of the sick leave was granted if the woman did not feel able to return to work. In such way we believe that sick leave expressed the woman's perceived experience of recovery. The 
symptoms pain and fatigue has been described as main contributors to prolonged postoperative convalescence [30]. We found that the sick leave and fatigue in a fast track setting was associated with stress coping capacity, but only in the group who had the operation performed in spinal anaesthesia. The HSC-G women who had SA had a sick leave that was far shorter than that for all other women. This group of women also presented with the lowest occurrence of fatigue. The length of sick leave and occurrence of fatigue for the LSC-G in SA was quite similar to the length of sick leave and occurrence of fatigue for all women in GA, independent of stress coping capacity.

The consumption of analgesics postoperatively has been shown to be associated with preoperative anxiety and coping strategies $[3,23,24]$. In the present study we found no association between consumption of analgesics and stress coping, independent of mode of anaesthesia. This may be due to our multimodal analgetic therapy combining paracetamol, NSAID and opioid whereas Kain et al. and Cohen et al. [3,23] only used intravenous patient controlled administration of morphine. All women in those studies had general anaesthesia and their dosage of morphine given during the 24-48 hours postoperatively exceeded by far the dosage of our patients in general anaesthesia. This could indicate that the multimodal analgesic therapy provided advantages by reducing the need of opioids, which is considered an advantage in the fast track program even for women with low stress coping capacity.

Preoperative psychological preparation of patients for surgery has been a common practice for many years. Patient education concerning postoperative care is an important element of the fast track concept, and it is claimed to play a major role in modifying the individual's response to the operative experience [7]. To the best of our knowledge no studies have analysed the effect of stress coping capacity on recovery in fast track surgery. However, our results need to be confirmed. Although some studies have shown associations between preoperative psychological characteristics and recovery results are ambiguous [8,31-37]. In 
our study it seemed that mode of anaesthesia played an important role for the stress coping capacity's importance for the recovery.

The study has methodological limitations. It constitutes a post hoc analysis and the results should be considered as exploratory. The participants in the trial were randomized to mode of anaesthesia and no stratification was done according to stress coping capacity. The number of women in the two categories of stress coping capacity would, according to the definition of the categories, be uneven and lowest in the LSC-G. Consequently this group determined the statistical power of the study. In order to reduce or eliminate the effects of confounding we applied the propensity score matching model to estimate treatment effects. Propensity score methods have in recent years increasingly been advocated to reduce the impact of treatment-selection bias in the estimation of treatment effects in studies using observational data [38]. It is a popular and effective way of dealing with confounding and is probably most useful in small studies where it is not possible to include a large number of possible confounding factors in the analysis. In this study we used the method of matching on the propensity score. This gave a group of women which should be relatively homogeneous with regard to the confounding factors, but concurrently unfortunately a much smaller number to use in the analysis. This might indicate a lower statistical power and consequently a possible reduced effect of the analysis but at the same time gives a lower risk of overestimating the results.

The results of the subgroup analyses should be interpreted with caution because of the relatively small number of women in these subgroups. In the fast track program it was stated that the participants should receive thorough information about perioperative care. Although the information was repeated pre-operatively and during hospital stay no assessments were performed to reassure that all participants had received the entire bulk of information or to 
what level the participant had understood it. This issue is always troublesome in clinical trials and may constitute a sort of selection bias.

In conclusion, psychological stress coping capacity seems to be of importance in fast tract abdominal hysterectomy when conducted in spinal anaesthesia. Women with high stress coping capacity had a sick leave shorter than three weeks and postoperative symptoms perceived less intensive and troublesome. It might be possible and desirable for the individual as well as the health care system to enhance recovery after surgery by intervention programs aiming to improve or manage stress coping for, in particular, individuals with low stress coping capacity. This merits further investigations. 


\section{Declaration of interest}

The authors report no conflicts of interest.

\section{Ethics approval}

The Regional Ethical Board at Linköping University (registration nr: M159-06, approval date 15 November 2006; amendment 1: registration nr T83-07, approval date 3 October 2007; amendment 2: registration nr T19-08, approval date 4 March 2008); and the Swedish Medical Products Agency (registration nr: EudraCT nr 2006-002520-41) approved the study.

\section{Funding}

The study was supported financially by grants from the Medical Research Council of South East Sweden; Linköping University and the County Council of Östergötland.

\section{Contribution to authorship}

NBW, LN and PK planned and conducted the study. The data were processed and analysed by PK, NBW, LN, MF and KW. PK and KW were the primary authors of the manuscript. All authors contributed to the elaboration of the manuscript, revised the paper and approved the final version. 


\section{References}

1. Nieboer TE, Johnson N, Lethaby A, Tavender E, Curr E, Garry R, et al. Surgical approach to hysterectomy for benign gynaecological disease. Cochrane Database Syst Rev 2009 Jul 8;(3):CD003677. 1-191.

2. Oates M, Gath D. Psychological aspects of gynaecological surgery. Baillieres Clin Obstet Gynaecol 1989;3(4):729-49.

3. Kain ZN, Sevarino F, Alexander GM, Pincus S, Mayes LC. Preoperative anxiety and postoperative pain in women undergoing hysterectomy. A repeated-measures design. $\mathrm{J}$ Psychosom Res 2000;49(6):417-22.

4. Donoghue AP, Jackson HJ, Pagano R. Understanding pre- and post-hysterectomy levels of negative affect: a stress moderation model approach. J Psychosom Obstet Gynaecol 2003;24(2):99-109.

5. Persson P, Kjølhede P. Factors associated with postoperative recovery after laparoscopic and abdominal hysterectomy. Eur J Obstet Gynecol Reprod Biol 2008;140(1):108-13.

6. Kehlet H. Multimodal approach to control postoperative pathophysiology and rehabilitation. Br J Anaesth 1997;78:606-17.

7. Kehlet H, Wilmore DW. Multimodal strategies to improve surgical outcome. Am J Surg 2002;183(6):630-41.

8. Miró J, Raich RM. Preoperative Preparation for Surgery: An Analysis of the Effects of Relaxation and Information Provision. Clin Psychol Psychother 1999; 6:202-9.

9. Borendal Wodlin N, Nilsson L, Kjølhede P; for the GASPI study group. The impact of mode of anaesthesia on postoperative recovery from fast-track abdominal hysterectomy: a randomised clinical trial. BJOG 2011;118(3):299-308. 
10. Borendal Wodlin N, Nilsson L, Årestedt K, Kjølhede P; for the GASPI study group. Mode of anesthesia and postoperative symptoms following abdominal hysterectomy in a fast track setting. Acta Obstet Gynecol Scand 2011;90(4):369-79.

11. Borendal Wodlin N, Nilsson L, Kjølhede P. Health-related quality of life and postoperative recovery in fast track hysterectomy. Acta Obstet Gynecol Scand 2011;90(4):362-8.

12. Ryding EL, Wijma B, Wijma K, Rydhström H. Fear of childbirth during pregnancy may increase the risk of emergency caesarean section. Acta Obstet Gynecol Scand $1998 ; 77: 542-7$

13. Persson P. On the mode of hysterectomy - with emphasis on recovery and well-being. Linköping University Medical Dissertations no. 1104. 2009. ISBN 978-91-7393-687-3

14. Söderquist J, Wijma B, Wijma K. The longitudinal course of post-traumatic stress after childbirth. J Psychosom Obstet Gynaecol 2006;27(2):113-9.

15. Beck AT, Beamesderfer A. Assessment of depression. The depression inventory. In P Pichot (Ed.) Psychological measurements in psychopharmacology. Modern problems in pharmacopsychiatry.1974. Paris: Karger, Basel.

16. Spielberger CD, Gorsuch RL, Lushene LE. Manual for the State-Trait Anxiety Inventory (self evaluation questionnaire). Palo Alto, CA. Consulting Psychologists Press, 1970.

17. Dupuy HJ. The psychological general well-being (PGWB) index. In: Wenger NK Mattson ME, Furberg CD, Elison J, eds. Assessment of quality of life in clinical trials of cardiovascular therapies. Le Jacq Publishing, 1984:170-84.

18. Hunter MS. The women's health questionnaire (WHQ): the development, standardisation and application of a measure of mid-aged women's emotional and physical health. Quality of Life Res 2000;9:733-8. 
19. Alkaissi A, Gunnarsson H, Johnsson V, Evertsson K, Ofenbartl L, Kalman S. Disturbing post-operative symptoms are not reduced by prophylactic antiemetic treatment in patients at high risk of post-operative nausea and vomiting. Acta Anaesthesiol Scand 2004;48:761-71.

20. Rubin DB. Estimating causal effects from large data sets using propensity scores. Annals of Internal Medicine 1997:127:757-63.

21. Guo S, Fraser MW. Propensity score analysis: Statistical methods and applications. SAGE Publications Inc, Thousand Oaks, Ca, USA 2010.

22. Boeke S, Stronks D, Verhage F, Zwaveling A. Psychological variables as predictors of the length of post-operative hospitalization. J Psychosom Res 1991;35(2-3):281-8

23. Cohen L, Fouladi RT, Katz J. Preoperative coping strategies and distress predict postoperative pain and morphine consumption in women undergoing abdominal gynecologic surgery. J Psychosom Res 2005; 58:201-9.

24. Ip HY, Abrishami A, Peng PW, Wong J, Chung F. Predictors of postoperative pain and analgesic consumption: a qualitative systematic review. Anesthesiology 2009;111(3):657-77.

25. Persson P, Brynhildsen J, Kjølhede P; Hysterectomy Multicentre Study Group in SouthEast Sweden. Short-term recovery after subtotal and total abdominal hysterectomy--a randomised clinical trial. BJOG 2010;117(4):469-78.

26. Rasmussen LS, Johnson T, Kuipers HM, Kristensen D, Siersma VD, Vila P et al. Does anaesthesia cause postoperative cognitive dysfunction? A randomised study of regional versus general anaesthesia in 438 elderly patients. Acta Anaesthesiol Scand $2003 ; 47(3): 260-6$

27. Rasmussen LS. Postoperative cognitive dysfunction: incidence and prevention. Best Pract Res Clin Anaesthesiol 2006;20:315-30. 
28. Krenk L, Rasmussen LS, Kehlet H. New insights into the pathophysiology of postoperative cognitive dysfunction. Acta Anaesthesiol Scand 2010;54(8):951-56.

29. Oxlad M, Stubberfield J, Stuklis R, Edwards J, Wade TD. Psychological risk factors for increased post-operative length of hospital stay following coronary artery bypass graft surgery. J Behav Med 2006;29(2):179-90.

30. Bisgaard T, Støckel M, Klarskov B, Kehlet H, Rosenberg J. Prospective analysis of convalescence and early pain after uncomplicated laparoscopic fundoplication. $\mathrm{Br} \mathrm{J}$ Surg. 2004;91(11):1473-8.

31. Müllender A, Melichar G, Schmucker P, Hüppe M. Psychological traits, course of surgery and recovery following hernia repair in patients preferring general or local anaesthesia. [In German]. Anaesthesist 2006;55(3):247-54.

32. Gan TJ. Risk factors for postoperative nausea and vomiting. Anesth Analg 2006;102(6):1884-98.

33. Cohen F, Lazarus RS. Active coping processes, coping dispositions and recovery from surgery. Psychosom Med 1973;35:375-89.

34. Miller SM, Mangan CE. Interacting effects of information and coping style in adapting to gynecologic stress: should the doctor tell all? J Pers Soc Psychol 1983;45(1):223-36.

35. Kopp M, Bonatti H, Haller C, Rumpold G, Söllner W, Holzner B, et al. Life satisfaction and active coping style are important predictors of recovery from surgery. J Psychosom Res 2003;55(4):371-7.

36. Perry F, Parker RK, White PF, Clifford PA. Role of psychological factors in postoperative pain control and recovery with patient-controlled analgesia. Clin J Pain 1994;10(1):57-63.

37. Taenzer P, Melzack R, Jeans ME. Influence of psychological factors on postoperative pain, mood and analgesic requirements. Pain 1986;24:331-42. 
38. Austin PC. A critical appraisal of propensity-score matching in the medical literature between 1996 and 2003. Stat Med. 2008;27(12):2037-49. 